\title{
POISONING BY ETHYL MERCURY TOLUENE SULPHONANILIDE
}

\author{
BY \\ M. A. JALILI and A. H. ABBASI \\ From the Department of Medicine, College of Medicine, University of Baghdad, Iraq
}

(RECEIVED FOR PUBLICATION JULY 2, 1961)

\begin{abstract}
Poisoning by a fungicide used for seed-borne diseases of cereals, ethyl mercury p-toluene sulphonanilide (Granoson M, Dupont), is described. It affected a large number of farmers and their families who used the dressed seed in the preparation of home-made bread. Many systems were involved, including the kidneys, the gastro-intestinal tract, the skin, the heart, and the muscles, but involvement of the nervous system was the most constant with disturbance of speech, cerebellar ataxia, and spasticity. Mental abnormalities were occasionally observed. Many patients died. The changes in the electrocardiograms are described and illustrated. The importance of effective measures for prevention and the need for further studies of treatment are stressed.
\end{abstract}

Mercury poisoning is nowadays comparatively rare, and when seen is generally the result of the medical use of, or accidental exposure to, the metal or its salts. However, when organic mercury compounds are used as fungicides against seed-borne diseases of cereals and are handled by a large number of farmers who are not used to such toxic materials, mercury poisoning is likely to occur.

Organic mercury compounds have been used to prevent seed-borne diseases of cereals since 1914 . Many different preparations of mercury are sold as fungicides and typical examples used widely are phenyl mercury acetate, ethyl mercury phosphate, and methyl mercury dicyandiamide. In the past few years ethyl mercury $p$-toluene sulphonanilide (Granosan M, Dupont) has been used in Iraq as a fungicide for seed wheat, and hundreds of cases of poisoning from this material occurred. The present communication deals with the clinical picture of the disease and the electrocardiographic changes.

\section{Incidence}

In 1956 many cases of mercury poisoning were observed in the North of Iraq, and more than 100 cases were admitted to Mosul Hospital with 14 deaths. In 1960, many farmers from the central part of Iraq were affected and 221 patients (106 males and 115 females) were admitted to one hospital in Baghdad. Other patients went into other hospitals. There were many deaths, and patients usually spoke about deaths in their own families and locality.
According to Dr. W. M. Ali (personal communication) 22 bodies were examined in the Medico-Legal Institute in Baghdad, and large amounts of mercury were found in the organs. For example, in the liver the level was $6.58 \pm 1.85 \mathrm{mg} . / 100 \mathrm{~g}$.

Patients admitted that they were warned against eating the wheat because it had been treated with a harmful material. Some of them washed it to rid it of the poison; and when they noticed that nothing happened to fowls that consumed it for a few days, they started eating it, sometimes mixed with larger amounts of untreated wheat or maize. People who had eaten the dressed wheat and remained well for some days or weeks, set a bad example to others who did not hesitate to consume the dressed wheat in the form of bread.

\section{Method and Materials}

Granosan M (Dupont) was mixed with seed wheat, $50 \mathrm{~g} . / 100 \mathrm{~kg}$. This commercial product contains $7 \cdot 7 \%$ ethyl mercury $p$-toluene sulphonanilide. Its total mercury content, as mercury metal, is $3.2 \%$. In October, November, and December 1955, the dressed seed was distributed to farmers in the North of Iraq and cases of poisoning appeared in January, February, March, and April 1956. One of us (M.A.J.) examined many such cases at Mosul Hospital. In the season of 1959-60 the dressed seed was distributed in the central part of Iraq, and many patients were admitted to Baghdad hospital in March and April, and to a lesser extent in the following months.

The present series consists of 26 cases examined by the 
authors. The patients were farmers or their wives and children from the rural areas of different parts of Iraq. Usually many members of the family were affected. Their ages ranged between 7 and 60 years with an average of $23 \pm 12$ years. One case occurred among the workers who dressed the wheat. In addition to the case history and clinical examination, the urine was examined; 12lead electrocardiograms were taken in 15 patients.

The following case records illustrate the condition.

\section{Case Reports}

Case A.-A landworker, aged 17, purchased the treated wheat from fellow farmers and mixed it with ordinary wheat. Ten days after eating the bread made from it symptoms began to appear. Most of his diet consisted of home-prepared bread. At first he experienced severe pain in the knees; 10 days later he had generalized deep-seated pains; three weeks later he developed pruritus in the soles, palms, and genitalia, and his vision was affected. Bowels moved once or twice daily; there was some oliguria and little cough with mucoid expectoration. He was admitted to hospital two months after the onset of symptoms. Examination revealed a thin patient, suffering from pain. There was a grey zone on two lower incisors, coarse twitchings in the limb muscles, muscular excitability on percussion of the muscles, tender muscles but no tenderness along the course of nerves; there was no oedema, jaundice, or anaemia. Heart, chest, and abdomen showed no clinical abnormality. Tendon reflexes were present and the plantars were flexor. There was no ataxia or nystagmus. Fundi showed no lesion at this stage. Urine contained a trace of albumin and uric acid crystals. Electrocardiogram was normal.

Case B.-A farmer aged 16, ate bread made from treated seed two months before admission. After six weeks he developed abdominal pain, headache, weakness of the legs, difficulty in walking, unsteadiness when standing, and progressive deterioration of vision. This was accompanied by polyuria and polydipsia. Two other brothers were similarly affected. On admission he was thin, with clear mentality, almost blind, and had slurred speech with marked ataxia. There was a little pallor of the temporal parts of the optic discs. There was some spasticity of the lower limbs, and the tendon reflexes were diminished. Plantar reflexes were flexor and abdominal reflexes absent. Pulse was 100/min. irregular; blood pressure $130 / 70 \mathrm{~mm}$. $\mathrm{Hg}$, and temperature $37^{\circ} \mathrm{C}$. No cardiac murmurs, or added sounds in the chest; liver and spleen were not palpable; there were cautery marks on the abdomen (in rural areas of Iraq cautery is often made for pain). Urine showed a trace of albumin and granular casts. Blood urea $45 \mathrm{mg} . / 100 \mathrm{ml}$., $\mathrm{Hb} 70 \%$ (Sahli), red blood cells numbered $3,800,000$, and white blood cells 9,800 . Electrocardiogram showed a shifting pace-maker.

The patient was treated with BAL and after five days his ataxia and vision markedly improved.

\section{Results and Discussion}

Table 1 gives the main symptoms and signs found in the 26 patients examined by the authors. It is evident that they differ from the symptoms and signs of poisoning by mercury or its inorganic salts. Mercury poisoning has followed application of ointments in isolated cases (Stoneman, 1958; Williams and Bridge, 1958). Infants have been poisoned from a calomel used in teething preparations (Wilson, Thomson, and Holzel, 1952). Ingestion of mercuric bichloride leads to two kinds of lesions: those of the gastro-intestinal tract due to its corrosive action and those due to the specific kidney involvement (Troen, Kaufman, and Katz, 1951). On the other hand the clinical picture of poisoning with organic mercurial compounds is said to be confined to damage of the central nervous system and consists of deafness, generalized ataxia, dysarthria, progressive visual deterioration, dysphagia, sphincteric incontinence, mental confusion, stupor, and death (Locket, 1957).

Hunter, Bomford, and Russell (1940) described four cases of poisoning by inhalation of methyl mercury compounds in a factory. In these cases, with the exception of tremor, symptoms of poisoning by metallic mercury, namely salivation, stomatitis, and erethism, were absent, and the nervous system alone was involved, with severe generalized ataxia, dysarthria, and gross constriction of the visual fields. In experiments on rats and a monkey, methyl mercury compounds caused a widespread degeneration of certain sensory paths of the nervous system; the peripheral nerves and the posterior spinal roots were affected first, and the spinal cord and certain neurones of the middle lobe of the cerebellum later. Acute degeneration and sometimes early fibrosis of the kidneys were found in these rats. Though much of the acute damage in man apparently subsides, necropsy suggests that localized cerebellar degeneration does occur (Hunter and Russell, 1954). Lundgren and Swensson (1949) have also described cases of poisoning by methyl mercury derivatives used as fungicides on grain.

The present series represents the severe cases of poisoning admitted to hospital. The clinical picture found in the cases seen in Mosul (northern Iraq) in 1956 and those seen in Baghdad in 1960, falls into the following groups, depending on the amount of the poison taken and the system or systems mainly involved:

1. Involvement of the kidneys.-Oliguria may develop at the beginning of the illness if large amounts are consumed. Oedema is rarely seen. Usually polyuria and polydypsia with loss of weight and sometimes dehydration develop. These were the main symptoms in 62 cases out of 86 in the north of Iraq (R. Tapponi, personal communication). In Tapponi's cases urine examination showed the 
TABLE 1

MAIN SYMPTOMS AND SIGNS

\begin{tabular}{|c|c|c|c|c|c|c|c|c|c|c|c|c|c|c|c|c|c|c|}
\hline \multirow[b]{2}{*}{$\begin{array}{l}\dot{c} \\
z \\
\tilde{y} \\
\tilde{U} \\
\end{array}$} & & \multicolumn{17}{|c|}{ Symptoms } \\
\hline & 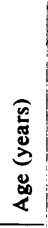 & 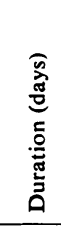 & $\begin{array}{l}\frac{\pi}{2} \\
\frac{3}{3} \\
0 \\
0\end{array}$ & 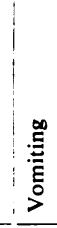 & $\begin{array}{l}\frac{n}{0} \\
\vdots \\
0 \\
0\end{array}$ & 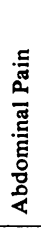 & 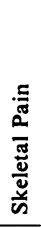 & 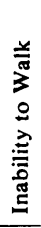 & 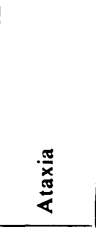 & 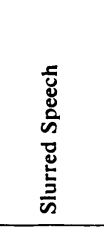 & 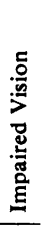 & 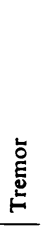 & 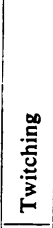 & 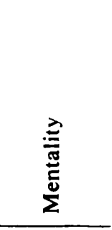 & 胥 & 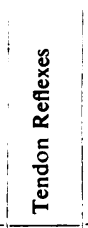 & 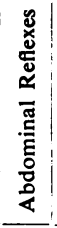 & 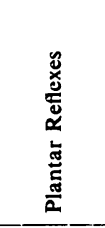 \\
\hline $\begin{array}{r}1 \\
2 \\
3 \\
4 \\
5 \\
6 \\
7 \\
8 \\
9 \\
10 \\
11 \\
12 \\
13 \\
14 \\
15 \\
16 \\
17 \\
18 \\
19 \\
20 \\
21 \\
22 \\
23 \\
24 \\
25 \\
26\end{array}$ & $\begin{array}{r}25 \\
7 \\
17 \\
22 \\
14 \\
35 \\
16 \\
10 \\
16 \\
23 \\
8 \\
25 \\
30 \\
9 \\
10 \\
16 \\
16 \\
35 \\
35 \\
40 \\
12 \\
35 \\
17 \\
20 \\
26 \\
35\end{array}$ & $\begin{array}{r}90 \\
7 \\
5 \\
7 \\
14 \\
10 \\
10 \\
40 \\
12 \\
7 \\
31 \\
32 \\
60 \\
10 \\
15 \\
15 \\
60 \\
15 \\
8 \\
120 \\
30 \\
15 \\
60 \\
90 \\
25 \\
60\end{array}$ & $\begin{array}{c}+ \\
+ \\
+ \\
+ \\
+ \\
\pm \\
- \\
+ \\
- \\
+ \\
+ \\
+ \\
+ \\
+ \\
+ \\
+ \\
- \\
- \\
+ \\
\text { Oliguria } \\
\text { Oliguria } \\
+\end{array}$ & $\begin{array}{l}+ \\
\pm \\
+ \\
+ \\
\pm \\
+ \\
- \\
+ \\
- \\
- \\
+ \\
- \\
- \\
+ \\
- \\
- \\
\pm \\
- \\
- \\
-\end{array}$ & \begin{tabular}{|c|} 
Diarrhoea \\
- \\
- \\
Diarrhoea \\
Diarrhoea \\
- \\
Diarrhoea \\
- \\
- \\
Diarrhoea \\
- \\
- \\
- \\
Constipation \\
- \\
- \\
Diarrhoea \\
Diarrhoea \\
- \\
- \\
- \\
Constipation \\
Constipation \\
Constipation \\
Constipation
\end{tabular} & $\begin{array}{l}\overline{+} \\
\overline{+} \\
+ \\
+ \\
\overline{+} \\
\overline{+} \\
+ \\
+ \\
+ \\
- \\
+ \\
+ \\
+ \\
- \\
- \\
+ \\
+ \\
+ \\
+ \\
+\end{array}$ & $\begin{array}{l}- \\
+ \\
+ \\
- \\
- \\
= \\
\overline{+} \\
- \\
\overline{+} \\
- \\
- \\
\overline{+} \\
- \\
\overline{+} \\
\overline{+} \\
+ \\
+ \\
+ \\
+ \\
+\end{array}$ & $\begin{array}{l}+ \\
+ \\
+ \\
+ \\
+ \\
+ \\
+ \\
+ \\
+ \\
+ \\
+ \\
+ \\
+ \\
+ \\
+ \\
+ \\
+ \\
+ \\
+ \\
+ \\
+ \\
+ \\
+ \\
+\end{array}$ & $\begin{array}{c}+ \\
\text { Drowsy } \\
+ \\
- \\
- \\
+ \\
- \\
+ \\
+ \\
+ \\
+ \\
+ \\
+ \\
+ \\
+ \\
+ \\
+ \\
+ \\
+ \\
- \\
+ \\
- \\
- \\
- \\
-\end{array}$ & $\begin{array}{c}+ \\
\text { Drowsy } \\
+ \\
\text { Aphasia } \\
\text { Aphasia } \\
+ \\
- \\
\text { Aphasia } \\
+ \\
\text { Aphasia } \\
+ \\
+ \\
+ \\
+ \\
+ \\
+ \\
+ \\
+ \\
- \\
- \\
= \\
- \\
- \\
-\end{array}$ & $\begin{array}{l}\bar{?} \\
+ \\
? \\
? \\
- \\
- \\
- \\
? \\
+ \\
+ \\
+ \\
+ \\
+ \\
+ \\
+ \\
+ \\
= \\
- \\
+ \\
+ \\
+ \\
+\end{array}$ & $\begin{array}{l}- \\
- \\
- \\
- \\
= \\
- \\
- \\
- \\
- \\
+ \\
\pm \\
- \\
- \\
\bar{z} \\
- \\
- \\
- \\
- \\
-\end{array}$ & $\begin{array}{l}- \\
- \\
- \\
- \\
= \\
= \\
= \\
- \\
- \\
- \\
- \\
- \\
- \\
- \\
++ \\
- \\
++ \\
+ \\
+ \\
+\end{array}$ & $\begin{array}{l}\text { Normal } \\
\text { Drowsy } \\
\text { Normal } \\
\text { Normal } \\
\text { Excitable } \\
\text { Normal } \\
\text { Normal } \\
\text { Normal } \\
\text { Normal } \\
\text { Psychotic } \\
\text { Normal } \\
\text { Normal } \\
\text { Normal } \\
\text { Normal } \\
\text { Normal } \\
\text { Normal } \\
\text { Normal } \\
\text { Euphoria } \\
\text { Psychotic } \\
\text { Normal } \\
\text { Normal } \\
\text { Normal } \\
\text { Normal } \\
\text { Normal } \\
\text { Normal } \\
\text { Normal }\end{array}$ & $\begin{array}{l} \pm \\
- \\
= \\
= \\
= \\
= \\
- \\
- \\
+ \\
- \\
- \\
- \\
- \\
- \\
+ \\
+ \\
+ \\
\pm \\
-\end{array}$ & $\begin{array}{c}++ \\
+++ \\
+++ \\
+++ \\
+ \\
+ \\
+++ \\
+ \\
+++ \\
+++ \\
+++ \\
+++ \\
+ \\
++ \\
+ \\
++ \\
+ \\
++ \\
+ \\
+ \\
+ \\
+ \\
+ \\
++\end{array}$ & $\begin{array}{l}+ \\
+ \\
+ \\
+ \\
+ \\
+ \\
+ \\
+ \\
+ \\
+ \\
+ \\
+ \\
+ \\
+ \\
+ \\
+ \\
+ \\
+ \\
+ \\
+ \\
+ \\
+ \\
+ \\
+ \\
+\end{array}$ & $\begin{array}{l}\text { Flexor } \\
\text { Extensor } \\
\text { Extensor } \\
\text { Extensor } \\
\text { Extensor } \\
\text { Extensor } \\
\text { Extensor } \\
\text { Flexor } \\
\text { Extensor } \\
\text { Extensor } \\
\text { Extensor } \\
\text { Extensor } \\
\text { Flexor } \\
\text { Flexor } \\
\text { Flexor } \\
\text { Flexor } \\
\text { Flexor } \\
\text { Flexor } \\
\text { Extensor } \\
\text { Flexor } \\
\text { Flexor } \\
\text { Flexor } \\
\text { Flexor } \\
\text { Flexor } \\
\text { Flexor } \\
\text { Flexor }\end{array}$ \\
\hline
\end{tabular}

Sequence of events and other findings:

Case 1: Dark pigmentation of skin and mucous membranes, with exfoliation of skin; ataxia, paraesthesiae; then polyuria and polydipsia. Case 2: Vomiting, abdominal pain, marked weakness of legs with paraesthesiae, spastic paraplegia. Case 3: After eating dressed seeds for one month developed severe polydipsia and polyuria with pain in legs and inability to walk. Spastic paraplegia, optic atrophy. Case 4: Vomiting, colic, diarrhoea, inability to speak or walk. Case 5: Abdominal colic, tarry stools, vomiting, asthenia, polyuria and polydipsia, incontinence of urine. Severely ill, with opisthotonos, severe excitement. Case 6: Abdominal pain; excessive salivation, weak legs, general spasticity, dysarthria. Case 7: Weakness of legs, vomiting, general spasticity. Case 8: Fever, abdominal pain, gradual aphasia and dysphagia, slight weakness of legs. Case 9: Gradual weakness of limbs, incontinence of urine, dysarthria; quadriplegia. Case 10: Vomiting, diarrhoea, abdominal colic, inability to walk or speak. Case 11: Abdominal pain, burning micturition, paraesthesiae, spastic paraplegia and slurred speech. Case 12: Headache, abdominal colic, burning micturition, paraesthesiae, slurred speech, spastic paraplegia. Case 13: Severe pain in hips and legs not responding to usual analgesics. Paraesthesiae, tremors; pruritus and exfoliation of legs and feet. Case 14: Polydipsia, vomiting, constipation, numbness, weakness of legs, unsteady gait, slight impairment of hearing, then blindness; spasticity; optic atrophy; oedema of legs. Case 15: Headache, dizziness, weakness of legs, unsteady gait, blindness; spasticity; optic atrophy. Case 16: Abdominal pain, headache, paraesthesiae, weakness of legs, severe ataxia, impaired vision and later optic atrophy. Case 17: Colic, diarrhoea, polydipsia, paraesthesiae, general pains especially in legs; inability to walk; atrophy of muscles of legs, no fasciculation, spasticity of limbs. Case 18: Vomiting, diarrhoea, abdominal colic, inability to walk; then euphoria, delirium, and hallucinations. Irregular pulse. Case 19: Dizziness and fainting, then generalized tremors, spasticity. Psychotic. Case 20: Pains in hips, legs and shoulder; aching bones. Case 21: Intense pruritus then melaena, marked loss of weight. Case 22: Pain in hips, legs, then abdominal pain, paraesthesiae; cauteries in abdomen and knees for pain. Blue gums, septic teeth. Case 23: Pain in knees then generalized, oliguria, grey zone on incisors. Case 24: Epigastric pain, pain in shoulders, back and legs, severe in legs; vertigo; marked sweating. Case 25: Dark urine, general oedema, later ascites; pain in back, chest, and legs, cough. Case 26: Backache, then pain in limbs; after these subsided abdominal pain appeared; marked muscular twitchings; cough and expectoration.

presence of a trace of albumin in $58 \%$, albumin + in $35 \%$, and albumin ++ in $6 \%$ of the samples. Hyaline casts were seen in $22 \%$, granular casts in $17 \%$, and waxy casts in $5 \%$. In $18 \%$ of the specimens a few red blood cells were seen. In severe cases the blood urea was much increased.

2. Skin lesions.-Pruritus is not uncommon, mainly in the palms, soles, and genitalia. In severe cases exfoliative dermatitis follows, especially of the hands and feet.
3. Nervous lesions. - These are almost constant in cases of all grades of severity. Loss of power in the legs and difficulty in walking or inability to walk are frequent. Cerebellar ataxia, disturbance of speech, paraplegia, or general spasticity with brisk reflexes are common. The plantars may be extensor while the abdominal reflexes are retained. Ankle clonus is occasionally present while tendon reflexes are lost. Restriction of visual fields or marked loss of vision with optic atrophy are not infrequent. Tremors or intention tremors are sometimes found. Para- 
esthaesiae are noticed by some patients but sensation remains intact.

4. Mental condition.-Mentality is usually not affected, but some patients lost consciousness and then died. A few patients had headache, insomnia, confusion, hallucinations, or excitement, and one woman wanted to throw her child from the balcony. Manic states were also seen.

5. Cardiac involvement.-In severe cases the pulse is irregular, sometimes with bradycardia. Electrocardiographic examination of severe cases showed frequent ventricular ectopic beats, prolongation of Q-T interval, depression of the S-T segment, and $\mathrm{T}$ inversion.

6. Deep skeletal pain.-This is generally felt over the muscles or bones and is frequent, sometimes very severe and not alleviated by the usual analgesics. The pain is usually generalized but is sometimes confined to the lower extremities and less often to the shoulders. Fasciculation and coarse twitching of muscles are also present. Myoidema is elicited in many cases.

7. Gastro-intestinal symptoms.-These are usually not very severe. Vomiting and/or diarrhoea are sometimes present; some cases have constipation. Epigastric or hypogastric pain or colic are also frequent. Two cases had melaena, and another two had dysphagia.

The symptoms and signs of poisoning by ethyl mercury toluene sulphonanilide are different from those caused by methyl mercury described by Hunter et al. (1940). In their cases no abnormality was noted in the cardiovascular system, the visual fields being constricted, and the fundi remaining normal; while in our cases the heart was affected and optic atrophy seen. Also their cases did not experience the skeletal pain, muscular twitching, polyuria, or skin changes which were frequent in the present series. It is interesting to note that the members of some families all had similar symptoms; for example three brothers admitted to hospital all had optic atrophy.

Fatal cases had severe involvement of the nervous system or cardiac abnormalities evidenced by the irregular pulse or electrocardiographic changes. Mild and moderately severe cases recovered. Unfortunately, when patients left hospital they could not be traced and no adequate follow-up was possible. It is possible that the disease was more serious in the cases we report because the patients' general health had already been undermined by endemic diseases, particularly ankylostomiasis (Jalili and
Demarchi, 1952), and the low protein, low vitamin diet on which they exist. Wheat and barley in the form of home-made bread provide a very large proportion of their diet (Jalili, Georges, and Fadhil, 1950; Jalili and Al-Kassab, 1959).

Some persons who consumed the dressed seed came to medical centres with no symptoms or signs; they sought medical advice because a member of their family had developed symptoms or had died.

An interval of a few weeks or months occurs between the distribution of the dressed seed and the appearance of cases of poisoning. This is partly due to the time needed for the cumulative effect of the poison to develop and partly to the fact that the farmers did not use the dressed seed for making bread immediately it was received, but only after their own stocks were exhausted, or after they found that others who consumed the seed had suffered no ill effects during the first few weeks.

Symptoms usually appeared within one or two months of eating the treated wheat, sometimes longer but occasionally in as short a time as a few days, depending on the amount consumed. Large amounts lead to the appearance of acute poisoning with gastro-intestinal symptoms and sometimes death.

\section{The Electrocardiograms}

Twelve-lead records were made for 15 patients; nine of these showed certain abnormalities (Table 2). The other six records were within normal limits. Impaired conduction evidenced by prolonged P-R interval, increased irritability of the heart with frequent ectopic beats, and severe myocardial damage shown by prolonged Q-T segment and S-T deviation with invertion of $\mathrm{T}$ waves were present singly or in combination (Figs. 1, 2, and 3).

\section{Treatment}

Supportive treatment with sedatives, analgesics, and vitamins was given. Pituitrin relieved polyuria and thirst in 10 out of 16 cases with improvement of the general condition ( $R$. Tapponi, personal communication). ACTH and cortisone were not helpful.

Dimercaprol (BAL) is effective in mercuric bichloride poisoning and should be given early (Longcope and Luetscher, 1946; Troen et al., 1951; Locket, 1957). Large doses are needed for the treatment of poisoning with mercury or its inorganic salts: $5 \mathrm{mg}$. $/ \mathrm{kg}$. body weight as an initial dose followed by three doses of $2.5 \mathrm{mg}$. $/ \mathrm{kg}$. body weight at three- or four-hourly intervals and a similar intramuscular dose given every six hours for the next 48 hours. Symptoms usually disappear within four weeks after contact with the poison. Neurological 


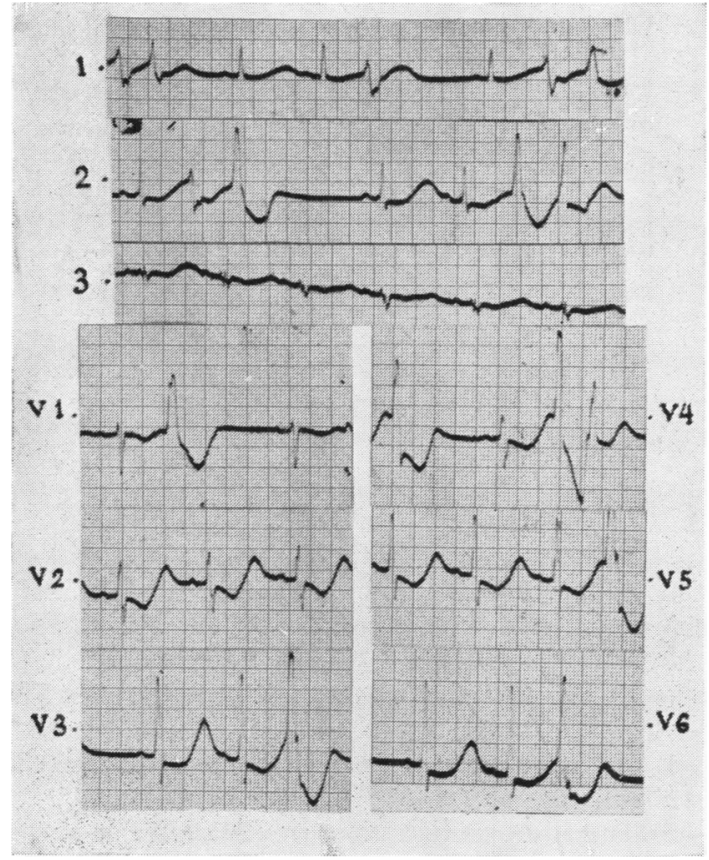

Fig. 1.-E.C.G. from a patient aged 35 years (Case No. 6). Symptoms of ethyl mercury toluene sulphonanilide poisoning of 10 days' duration.

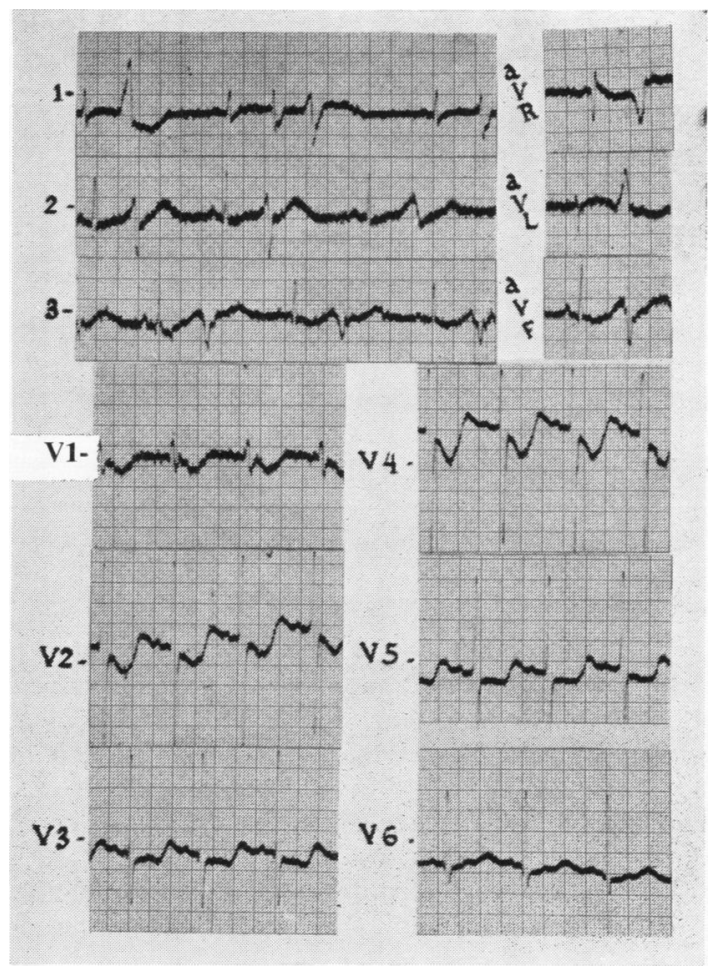

Fig. 2.-E.C.G. from a patient (Case No. 5) aged 14 years who had symptoms of poisoning for 14 days. She was seriously ill and died shortly after the record was taken.

Fig. 3.-E.C.G. from a patient 16 years of age (Case No. 17) with symptoms of poisoning of 15 days' duration who made an excellent recovery.

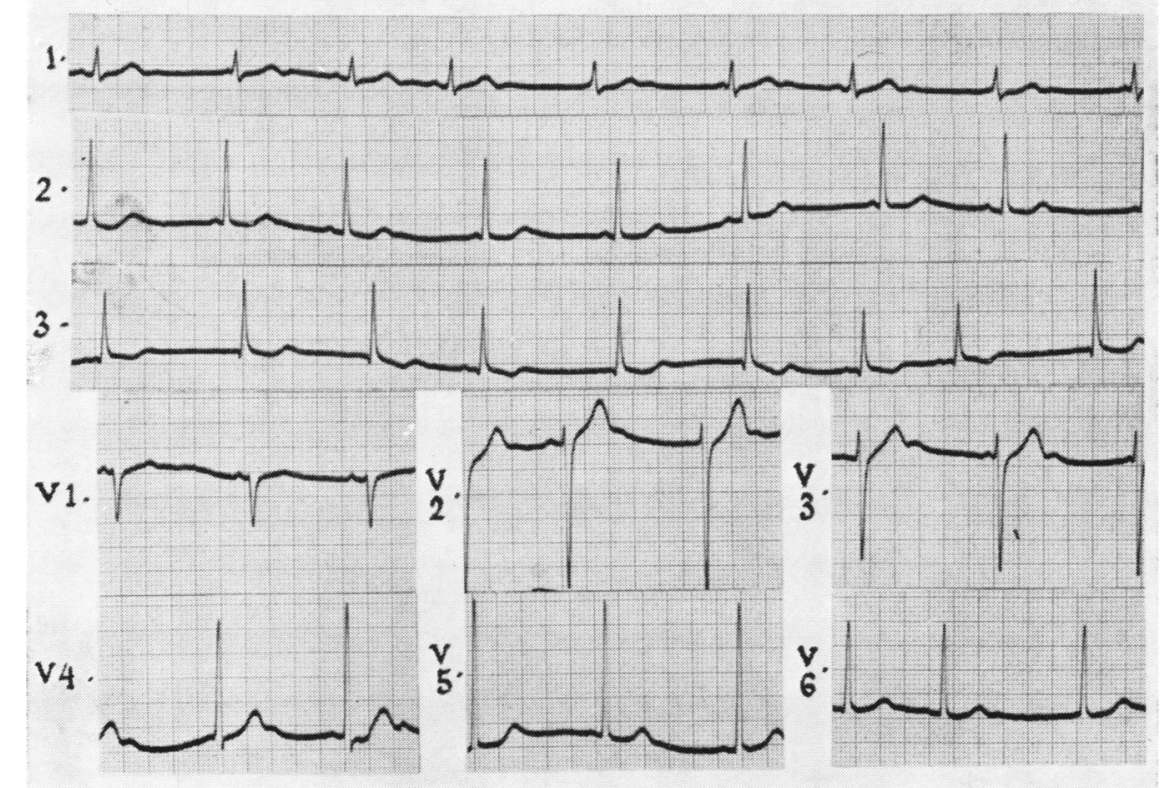


TABLE 2

FINDINGS IN ABNORMAL ELECTROCARDIOGRAMS

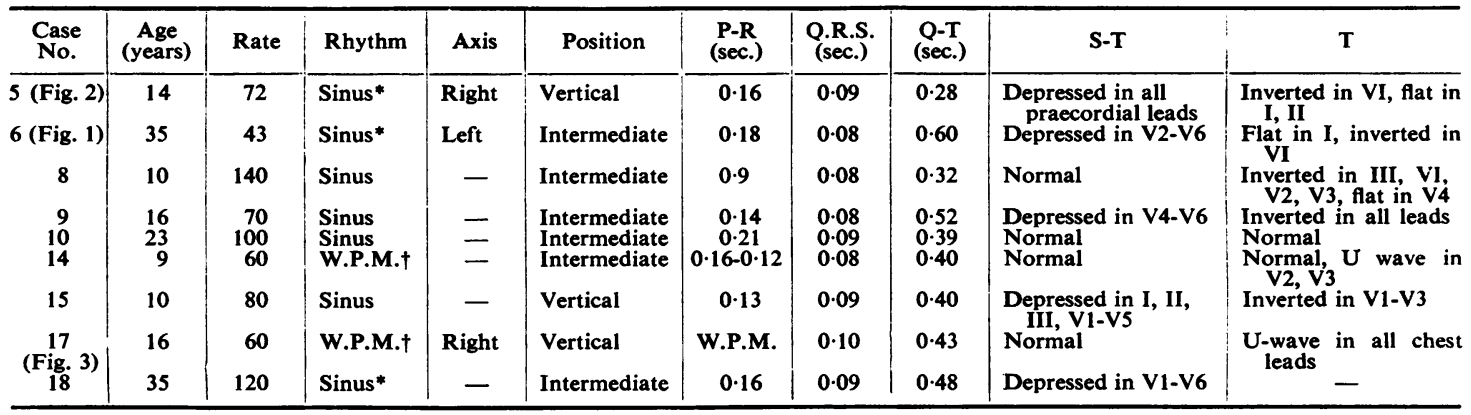

*Sinus rhythm with multifocal ventricular ectopic beats. Rate of dominating rhythm.

+Wandering pace-maker.

phenomena occasionally persist and may be due to continued unnoticed contact, psychological factors, or, rarely, to persistent damage of the central nervous system, as mercury has been detected in the cerebrospinal fluid a few months after the cessation of exposure. In chronic cases smaller doses of BAL may hasten recovery.

BAL is not expected to have any appreciable effect in poisoning with alkyl-mercury compounds because they produce toxicity as such and not as the result of the dissociated mercury.

BAL was used in many cases and our general impression is that it did not influence the course of the disease. However, it is difficult to ascertain its value where progress is so unpredictable. In five cases it had no appreciable effect, but in two cases it was accompanied by a rapid improvement in symptoms and signs. One of these had severe ataxia and was almost blind, but five days after the institution of BAL therapy he was able to walk well and his vision was greatly improved. BAL was given in a dosage of $100 \mathrm{mg}$. four-hourly for two days and eight-hourly for another 10 days. Apart from slight restriction of the visual fields and pallor of the temporal halves of the optic discs the patient made a complete recovery. In another case severe pain of sciatic distribution and exfoliative dermatitis of the legs quickly disappeared on BAL therapy. The pain did not respond to analgesics. Further experience with BAL in cases of poisoning by this type of mercury compound is needed.

\section{Prevention}

Organic mercury compounds are used as seed disinfectants of wheat, oats, other cereals, and for cotton and sugar beet. It is therefore necessary to take preventive measures against poisoning. The following measures are suggested:

1. Education of the population at risk using all available means.

2. The addition of a colouring material or a substance with an unpleasant taste to the fungicidal compound. This would make it almost impossible to use the dressed seed as food.

3. The protection of workers during dressing of the seed, which should be carried out in a completely enclosed apparatus.

4. Seed should be distributed immediately before the sowing season and used for this purpose only.

\section{REFERENCES}

Hunter, D., Bomford, R. R., and Russell, D. S. (1940). Quart. J. Med., n.s., 9, 193.

-, and Russeli, D. S. (1954). J. Neurol. Psychiat., 17, 235.

Jalili, M. A., and Al-Kassab, S. (1959). Lancet, 2, 108.

-, and Demarchi, M. (1952). J. Fac. Med. Iraq, 16, 71.

Locket, S. (1957). Clinical Toxicology, p. 572. Henry Kimpton, London.

Longcope, W. T., and Luetscher, J. A. Jr. (1946). J. clin. Invest., $25,557$.

Lundgren, K-D, and Swensson, A. (1949). J. industr. Hyg., 31,

Stoneman, M. E. R. (1958). Lancet, 1, 938.

Troen, P., Kaufman, S. A., and Katz, K. H. (1951). New Engl. J. Med., 244, 459.

Williams, N. E., and Bridge, H. G. T. (1958). Lancet, 2, 602

Wilson, V. K., Thomson, M. L., and Holzel, A. (1952). Brit. med. J., $\mathbf{i}, 358$. 